Original Article

\title{
An alternative method to reduce anaphylaxis by moxibustion
}

\author{
Hyun-Ja Jeong ${ }^{1, \dagger}$, Sun-Young Nam ${ }^{2, \dagger}$, Byong-Joo Lee ${ }^{2}$, Min-Gi Kim², Jeong-Hwa Kim³ ${ }^{3}$ Hyung-Min Kim,"* \\ 1Biochip Research Center and Inflammatory Disease Research Center, Hoseo University, 165, Sechul-ri, Baebang-myun, Asan, \\ Chungnam 336-795, Republic of Korea; 2Department of Pharmacology, College of Korean Medicine, Kyung Hee University, 1 \\ Hoegi-dong, Dongdaemun-gu, Seoul, 130-701, Republic of Korea; 3Graduate School of Social Welfare, Ewha Womans University, \\ 11-1 Daehyun-dong, Seodaemun-gu, Seoul, 120-750, Republic of Korea
}

\begin{abstract}
Epinephrine is a critical drug for patients at risk for anaphylaxis. Here, we suggest moxibustion as an alternative method to reduce anaphylaxis. Moxibustion was applied to the Shimen (CV5) acupoint and found to attenuate compound 48/80-induced mortality. Capsazepine, a transient receptor potential vanilloid (TRPV) 1 antagonist, significantly improved overall survival rates compared to groups treated with moxibustion or 2-aminoethoxydiphenyl borate (an activator of TRPV1, 2, and 3). Probenecid (a TRPV2 agonist) also increased survival rate and reduced histamine levels. Survival rates increased by moxibustion and probenecid were completely inhibited by ruthenium red (a TRPV2 and 3 antagonist) and gadolinium chloride (general TRPV antagonist), respectively. Passive cutaneous anaphylaxis and ear swelling were significantly reduced by moxibustion and probenecid ( $\mathrm{p}<0.05$ ). In cardiomyocytes, TRPV2 was over-expressed by compound 48/80 and histamine but this increased TRPV2 expression decreased to baseline with moxibustion and probenecid treatment. In addition, intracellular calcium levels increased by compound 48/80 were reduced by probenecid. Overall, these findings suggest that the reduction of anaphylaxis caused by moxibustion could represent a new mechanism of moxibustion related to the regulation of TRPV2 activation and promotion of epinephrine secretion.
\end{abstract}

Keywords anaphylaxis, moxibustion, transient receptor potential vanilloid2, epinephrine

\section{INTRODUCTION}

Anaphylaxis is serious systemic hypersensitive allergic reaction caused by histamine release from mast cells in the cardiovascular system, skin, respiratory tract, and gastrointestinal tract (Johansson et al., 2001; Kim et al., 2013). Because of the potential risk of death, it is critical to recognize anaphylaxis quickly and treat it appropriately. For the management of acute anaphylaxis, an open airway should be maintained. Vascular collapse and angioedema should be treated with epinephrine (Kim et al., 2013; Schummer et al., 2004).

Moxibustion, based on Traditional Oriental Medicine, is a treatment that applies dried Artemisia princeps Pampanini to acupoint on the skin and uses a fire to warm acupoints (Choi et al., 2004). Artemisia princeps Pampanini is a group of perennial herbal plant with more than 400 species and approximately 40 species of them are found in Korea. It was known to have a protective effect against gastric injury and oxidative stress caused by amyloid b peptide, antiwrinkle,

Correspondence: Hyung-Min Kim

E-mail: hmkim@khu.ac.kr

${ }^{\top}$ The author contributed equally to this work.

Received March 15, 2014; Accepted May 8, 2014; Published May 31,2014

doi: http://dx.doi.org/10.5667/tang.2014.0011

(C)2014 by Association of Humanitas Medicine

This is an open access article under the CC BY-NC license.

(http://cerativecommons.org/licenses/by-nc/3.0/) antimalarial, anti-helminthes, antiinflammation, and antimicrobial activities (Lee et al., 2011). Moxibustion is believed to regulate qi-blood and has been used to prevent and cure various diseases (Deng and Shen, 2013). Moxibustion mechanisms are related to its thermal effects, radiation effects, and the pharmacological actions of moxa and its combustion products (Deng and Shen, 2013). Moxibustion lead to vasoconstriction at the burning point and vasodilatation around the point, increasing peripheral arterial blood flow and microvacular permeability (Okazaki et al., 1990; Takayama et al., 2011). The thermal stimulation from moxibustion affects both shallow and deep tissues. Okazaki et al. (1990) confirmed that single cone $(2 \mathrm{mg}$ ) moxibustion on the murine abdomen can raise the temperature to $130^{\circ} \mathrm{C}$ at the point outside the skin and $56^{\circ} \mathrm{C}$ inside the skin.

Transient receptor potential vanilloid (TRPV), especially the 1 - 3 subtypes, is thermorecptor that senses physiological stimuli such as heat, protons, osmolarity, and physical stretch (Hu et al., 2004). In addition, in the vascular system, they affect vasoconstriction and vasodilatation (Inoue et al., 2008). TRPV2 was originally isolated as a molecule sensitive to temperatures above $52^{\circ} \mathrm{C}$ but has since been shown to be sensitive to some chemicals and mechanical stimuli (Caterina et al., 1999; Hu et al., 2004; Muraki et al., 2003; Shibasaki et al., 2010). TRPV2 has been detected in the brain, autonomic ganglia, spinal cord, skeletal and vascular myocytes, visceral organs (including the intestine, pancreas, spleen, and bladder), and blood cells (Caterina et al., 1999; Lewinter et al., 2008; Muraki et al., 2003). Mechanosensitivity of TRPV2 was first reported in 


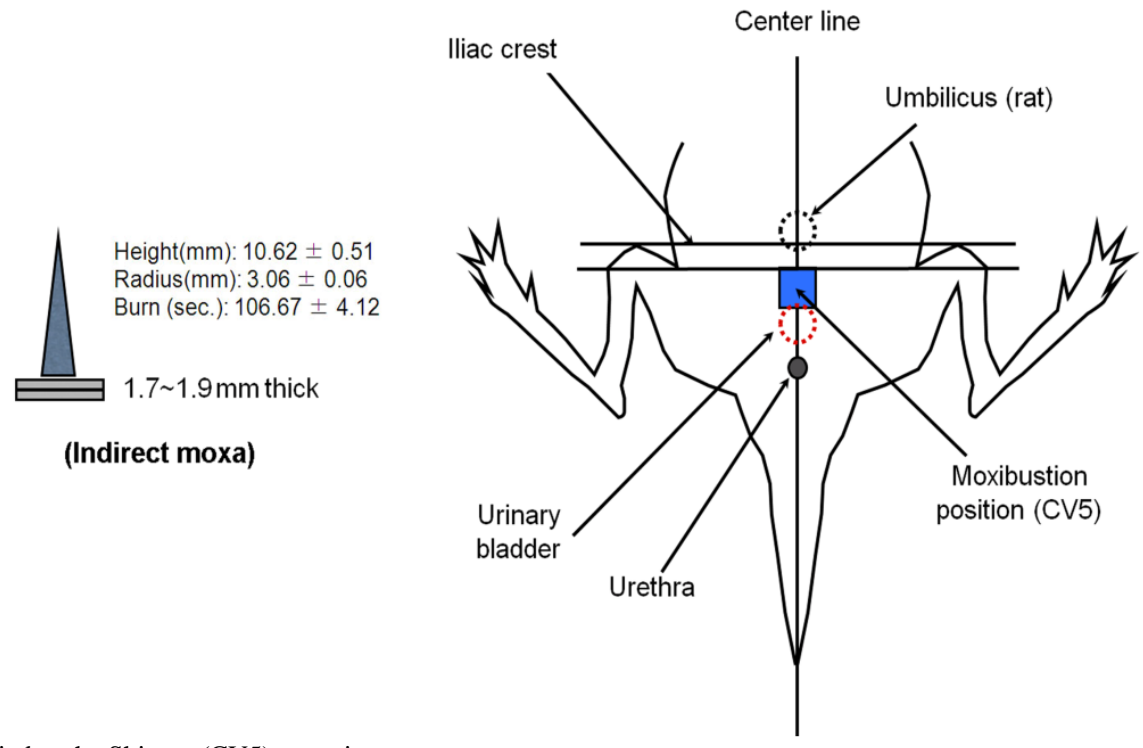

Fig. 1. Moxibustion was applied to the Shimen (CV5) acupoint.

cardiomyocytes (Muraki et al., 2003).

Anaphylaxis causes vasodilatation and hypotension (Johansson et al., 2001). Epinephrine has been described as the drug of choice for the treatment of hypotension from anaphylaxis, but the increased heart rate caused by epinephrine may be poorly tolerated (Weissgerber, 2008). In this study, the effect and specific mechanisms of moxibustion on anaphylaxis animal models and in primary cultured cardiomyocytes were investigated.

\section{MATERIALS AND METHODS}

\section{Reagents}

We purchased compound 48/80, probenecid (TRPV2 agonist), capsazepine, gadolinium chloride (TRPVs blocker), 2aminoethoxydiphenyl borate (2-APB), ruthenium red, phentolamine methanesulfonate salt, metoprolol tartrate salt, anti-dinitrophenyl (DNP)-IgE, DNP-human serum albumin (HSA), 3-(4,5-dimethylthiazol-2-yl)-2,5-diphenyltetrazolium bromide (MTT), dimethyl sulfoxide (DMSO), phosphatebuffered saline (PBS), bovine serum albumin (BSA), ophthaldialdehyde (OPA), Fura-2/AM, epinephrine assay kit, and evans blue from Sigma Chemical Co. (St. Louis, MO, USA); Dulbecco's modified Eagle's medium (DMEM), penicillin, streptomycin, and fetal bovine serum (FBS) from Gibco BRL (Grand Island, NY, USA); TRPV2 and actin antibodies from Santa Cruz Biotechnology (Santacruz, CA, USA); Sarcomeric- $\alpha$ actinin antibody from AB cam (Cambridge, England); Fluorescein isothiocyanate (FITC)-

Table 1. Survival (\%) by time course of moxibustion after compound $48 / 80$ treatment in mice

\begin{tabular}{lcccl}
\hline & Com 48/80 & 0 $\mathbf{~ m i n}$ & $\mathbf{5}$ min & $\mathbf{8}$ \\
\hline $\mathbf{1 0}$ min $>$ & 100 & 100 & 100 & 100 \\
$\mathbf{1 5}$ min $>$ & 100 & 100 & 75 & 87.5 \\
$\mathbf{2 0}$ min $>$ & 25 & 37.5 & 50 & 75 \\
$\mathbf{2 5}$ min $>$ & 0 & 12.5 & 50 & 62.5 \\
$\mathbf{3 0}$ min $>$ & 0 & 12.5 & 50 & 50 \\
$\mathbf{3 5}$ min $>$ & & 12.5 & 50 & 50 \\
\hline $\mathrm{n}=8$ & & & &
\end{tabular}

Com 48/80, compound 48/80 conjugated anti-rabbit IgG and tetramethylrhodamine-5-(and6)-isothiocyanate (TRITC)-conjugated anti-mouse IgG antibodies from Invitrogen (Carlsbad, CA, USA); moxibustion from Gangwhasazabal (Gangwha, Korea).

\section{Animals}

The original stock of male ICR mice (4 weeks old) and male SD rats ( 7 weeks old) were purchased from the Dae-Han Experimental Animal Center (Eumsung, Republic of Korea), and the animals were maintained at the College of Korean Medicine, Kyung Hee University. Animal care and experimental procedures were performed under the approval of the animal care committee at Kyung Hee University [Approval no. KHUASP (SE)-13-019]. The animals were housed five to ten per cage in a laminar air-flow room maintained at a temperature of $22 \pm 1{ }^{\circ} \mathrm{C}$ and a relative humidity of $55 \pm 1 \%$ throughout the study. No animal was used more than once. The research was conducted in accordance with internationally accepted principles for laboratory animal use and care as found in US guidelines (NIH publication \#85-23, revised in 1985).

\section{Compound 48/80-induced systemic anaphylaxis}

The mice were given an intraperitoneal (i.p.) injection of compound 48/80 (mast cells degranulator, $8 \mathrm{mg} / \mathrm{kg}$ ) and then moxibustion was applied (moxa, $10.62 \mathrm{~mm}$ long and in the diameter of $3 \mathrm{~mm} ; 1,2$, or 3 times stimulation), indirectly to stimulate at the Shimen (CV5) acupoint on the ventral midline of the mouse and rat for 0,5 , and $8 \mathrm{~min}$. The mice were kept in a holder for the duration of the stimulation time. Mortality was monitored for $30 \mathrm{~min}$ after induction of anaphylactic shock. 2APB $(60 \mathrm{mg} / \mathrm{kg}$, i.p.) and probenecid $(30,100$, and $300 \mathrm{mg} / \mathrm{kg}$, i.p.) were administered after compound 48/80. Capsazepine (10 $\mathrm{mg} / \mathrm{kg})$, gadolinium chloride $(10 \mathrm{mg} / \mathrm{kg})$, ruthenium red $(50$ $\mathrm{mg} / \mathrm{kg}$ ), and adrenergic receptor blockers [mixture of phentolamine $10 \mathrm{mg} / \mathrm{kg}$ (nonselective alpha-adrenergic receptor antagonist) and metoprolol $20 \mathrm{mg} / \mathrm{kg}$ (selective $\beta_{1}$ receptor blocker)] were intraperitoneally administered for $30 \mathrm{~min}$ before compound $48 / 80$ or probenecid $(300 \mathrm{mg} / \mathrm{kg})$ treatment. To assess the thermal effect on anaphylaxis, a soldering instrument at the same temperature as moxibustion was used for treatment. 
a

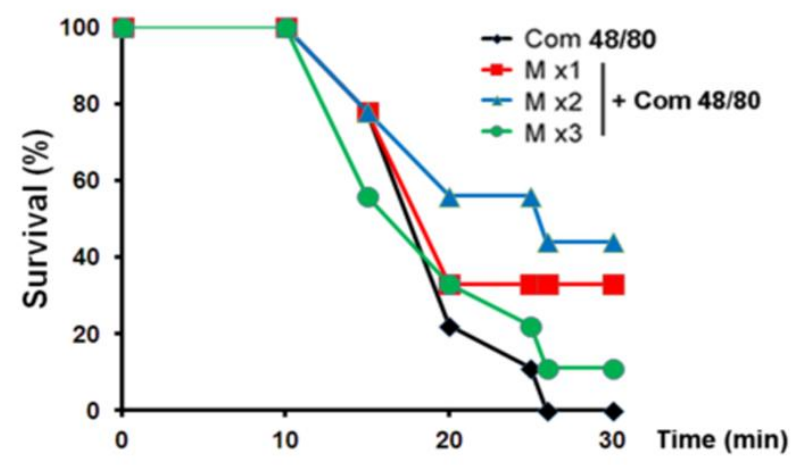

b

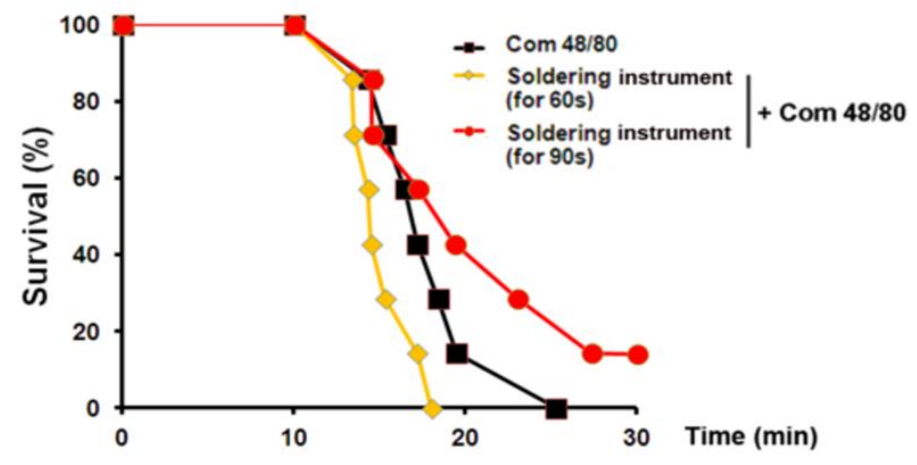

C

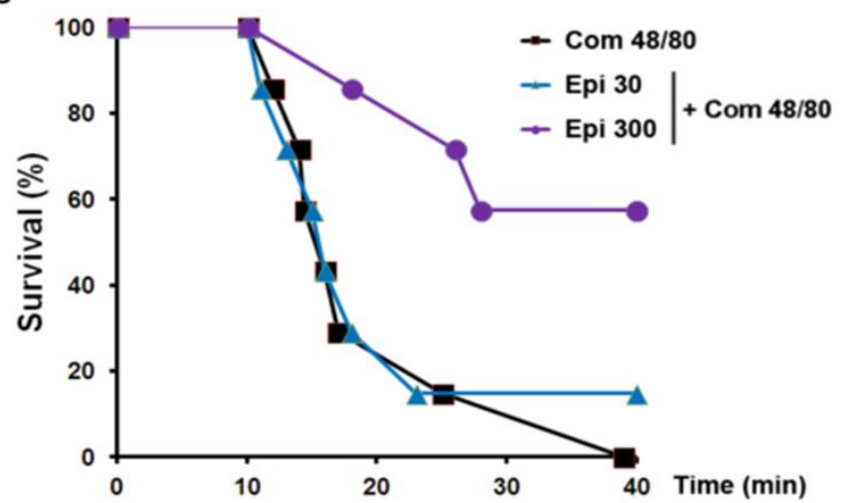

Fig. 2. Effect of moxibustion on anaphylaxis. Mice were given an intraperitoneal injection of the mast cell degranulator, compound $48 / 80(8 \mathrm{mg} / \mathrm{kg})$. Moxibustion was post-applied indirectly to stimulate at the Shimen (CV5) acupoint. (a) Survival (\%) was monitored for 30 min after induction of anaphylactic shock $(\mathrm{n}=9)$. (b) The soldering instrument was used for post-treatment at the same temperature as moxibustion $(\mathrm{n}=7)$. Survival $(\%)$ was monitored for $30 \mathrm{~min}$. (c) Epinephrine (30 and $300 \mu \mathrm{g} / \mathrm{kg}$ ) was post-stimulated after $5 \mathrm{~min}$ of compound 48/80 treatment $(\mathrm{n}=7)$. Com 48/80, compound 48/80; M, moxibustion; Epi, epinephrine.

\section{Passive cutaneous anaphylaxis $(\mathrm{PCA})$ reaction}

An IgE-dependent cutaneous reaction was generated by sensitizing the skin with an intradermal injection of anti-DNP IgE followed $48 \mathrm{~h}$ later with an injection of DNP-HSA into the mouse tail vein. Moxibustion was applied to the CV5 acupoint after DNP-HSA injection and probenecid was administered to some mice $1 \mathrm{~h}$ prior to DNP-HSA injection. The amount of dye was determined colorimetrically. The absorbent intensity of the extraction was measured at $620 \mathrm{~nm}$ in a spectrofluorometer, and the amount of dye was calculated with the Evans blue measuring-line.

\section{Compound 48/80- induced ear swelling response}

In this study, ear thickness was measured with a digimatic micrometer (Mitutoyo, Japan) under mild anesthesia. The ear swelling response was determined through any increment in thickness above the baseline control values. Compound 48/80 $(100 \mu \mathrm{g} / \mathrm{site})$ was freshly dissolved in saline and injected intradermally into the dorsal aspect of the mouse ear using a microsyringe with a 28 -gauge hypodermic needle. To assess any protective effects from moxibustion or probenecid, moxibustion was applied to the CV5 acupoint after compound $48 / 80$ treatment and probenecid was administered to some mice $1 \mathrm{~h}$ prior to compound $48 / 80$. The values obtained represent the effect of compound 48/80 rather than the effect of saline injection (physical swelling), since the ear swelling response 
a

Moxibustion x2

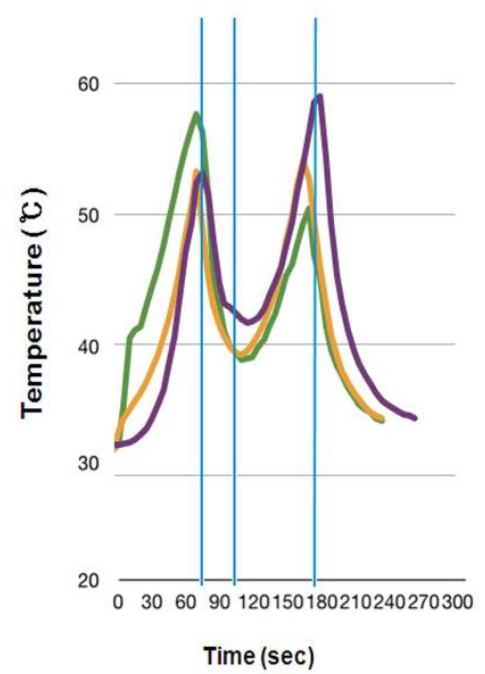

b

\section{Soldering instrument}

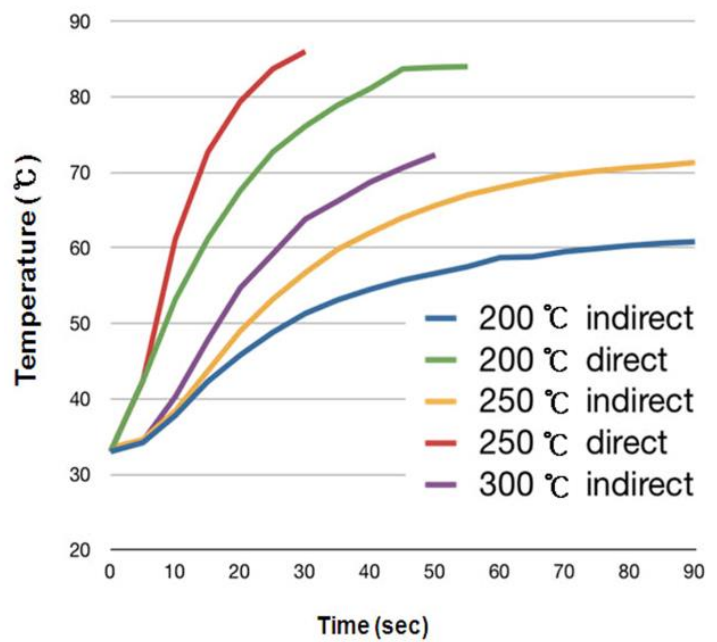

Fig. 3. Stimulation temperature of moxibustion and the soldering instrument. (a) Moxibustion and (b) Soldering instrument.

evoked by physiologic saline returned to baseline thickness within $40 \mathrm{~min}$.

\section{Histamine assay}

Histamine levels in serum were measured using the OPA spectrofluorometric procedure. The fluorescent intensity was measured at $440 \mathrm{~nm}$ (excitation at $360 \mathrm{~nm}$ ) in a spectrofluorometer.

\section{Epinephrine assay}

Epinephrine levels in serum were measured according to the manufacturer's specification using the Epinephrine Assay Kit (Sigma Chemical Co.).

\section{Blood pressure measurement}

Water was removed for $12 \mathrm{~h}$ and the rats were anesthetized with zoletil $50 \AA$ and rumpun ${ }^{\circledR}$ in a $1: 2$ ratio solution $1 \mathrm{ml} / \mathrm{kg}$. During anesthesia, one of the external iliac arteries was catheritized by laboratory PolyE polyethylene non-sterile tubing (\#598321, Havard Apparatus, USA) and connected to an iWorx 214 (iworx system, USA) with a research grade pressure transducer (Havard Apparatus, USA) using LabScribe2 software (iworx system, USA). Five to thirty $\min$ after stabilization, compound $48 / 80$ and probenecid were administered and the blood pressure was recorded. Data gained at $20 \mathrm{~Hz}$.

Reverse transcriptase-polymerase chain reaction (RT-PCR) analysis

Using an easy-BLUE ${ }^{\mathrm{TM}}$ RNA extraction kit (iNtRON Biotech, Republic of Korea), total RNA was isolated from organ tissues according to the manufacturer's specifications. The concentration of total RNA in the final eluate was determined by spectrophotometry. PCR was performed with the following primers: TRPV2 (5' CTA CAG CAA AGC CGA AAA GG 3'; 5' ACC GCA TGG TGG TTT TAG AG 3'); atrial natriuretic peptide (ANP) 5' AGG ATT GGA GCC AGA GTG G 3'; 5' ATA GAT GAA GGC AGG AAG C 3'); WINK4 (5' TGC CTT GTC TAT TCC ACG GTC TG 3'; 5' CAG CTG CAA TTT CTT CTG GGC TG 3'); and sodium chloride cotransporter (NCC) (5' TGA TGC GGA TGT CAT TGA TGG 3'; 5' AAT GGC AAG GTC AAG TCG 3'). To verify that equal amounts of RNA were used for the reverse transcription and PCR amplification from different experimental conditions, GAPDH (5' GGC ATG GAC TGT GGT CAT GA 3'; 5' TTC ACC ACC ATG GAG AAG GC 3') was used as a loading control. The products were electrophoresed on a $1.0 \%$ agarose gel and visualized by staining with ethidium bromide.

\section{Quantitative real-time PCR analysis}

Quantitative real-time PCR was performed using a SYBR Green master mix and the detection of mRNA was analyzed using an ABI StepOne real time PCR System (Applied Biosystems, Foster City, CA, USA). Primer sequences for the reference gene GAPDH and the genes of interest were as follows: GAPDH (5' GTT AGT 8 (ADR $\alpha 2 \mathrm{~A})(5$ ' TGT AGA TAA CAG GGT TCA GCG A 3'; 5' TTC TTT TTC ACC TAC ACG CTC A 3'); beta-1 adrenergic receptor (ADR $\beta 1$ ) (5' TGG CTT ACT GGC TTG TCTT G 3'; 5' TTT CCA CTC GGG TCC TTG 3'); and ANP (5' AGG ATT GGA GCC AGA GTG G 3'; 5' ATA GAT GAA GGC AGG AAG C 3'). Typical profile times were used the initial step of $95^{\circ} \mathrm{C}$ for 10 min was followed by a second step at $95^{\circ} \mathrm{C}$ for $10 \mathrm{~s}$ for 40 cycles with a melting curve analysis. The levels of target mRNA were normalized to GAPDH levels and compared to the control. Data were analyzed using the $\Delta \Delta C T$ method.

\section{Embryonic cardiomyocytes isolation}

Pregnant mice were euthanized by $\mathrm{CO} 2$ asphyxiation. The embryos (12 days old) were isolated from the uterus and then transferred into a dish with ice-cold sterile PBS without $\mathrm{Ca}^{2+}$ and $\mathrm{Mg}^{2+}$. The embryos were released from the yolk sacs and then transferred into another dish with the same solution as described above. Every single heart was isolated under a microscope using surgical instruments. The heart was incubated at $4{ }^{\circ} \mathrm{C}$ for $20 \mathrm{~h}$ and subsequently at $37^{\circ} \mathrm{C}$ for $15 \mathrm{~min}$ in a solution of $0.05 \%$ trypsin and $0.02 \%$ EDTA (wt/vol) (Biochrom AG). The tissue-trypsin-EDTA-mix was included in $1 \mathrm{ml}$ of DMEM (DMEM high glucose $(4.5 \mathrm{~g} / \mathrm{l})$ without L-glutamine with $10 \%$ fetal calf serum and $1 \%$ each of penicillin and streptomycin (Biochrom AG). To dissociate the heart, the tissue was gently pipetted several times. The mix gained by this procedure contains fibroblasts and cardiomyocytes. The cells within the medium from each heart of the same genotype were 

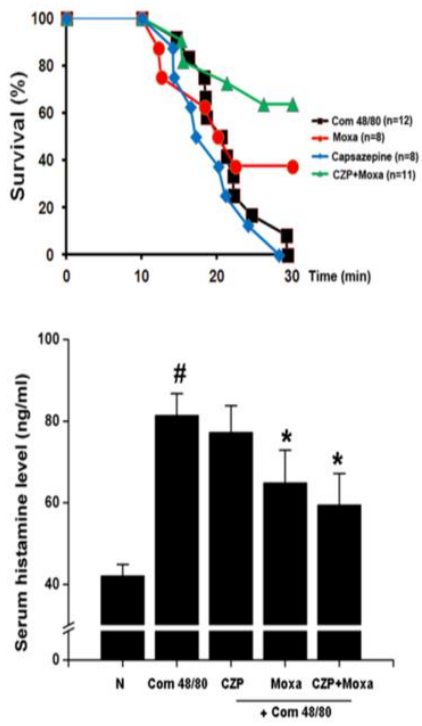
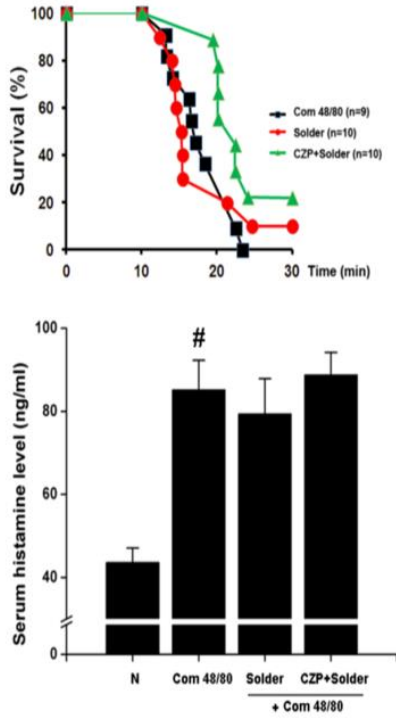
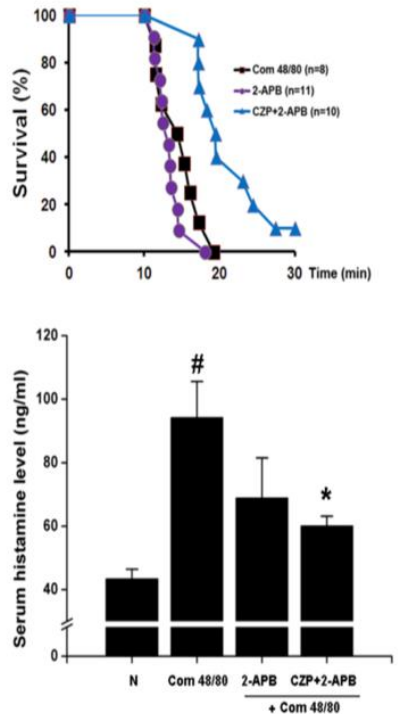
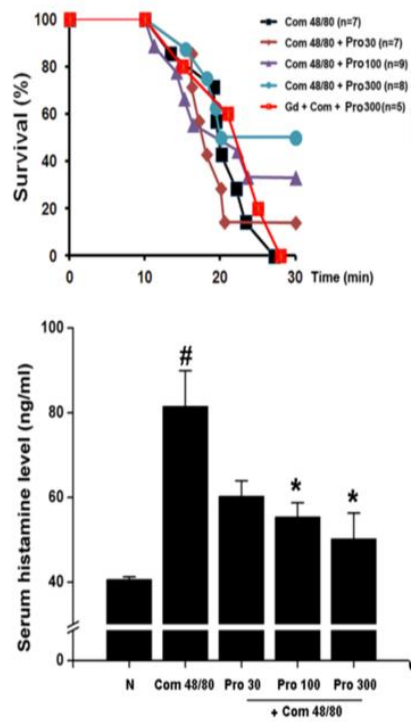

Fig. 4. Activation of TRPV2 by moxibustion in anaphylaxis. (a) Capsazepine pre-treatment (10 mg/kg) was given $30 \mathrm{~min}$ before stimulation with compound 48/80 and moxibustion. (b) Capsazepine pre-treatment (10 mg/kg) was given 30 min before stimulation with compound $48 / 80$ and a soldering instrument. (c) Capsazepine pre-treatment $(10 \mathrm{mg} / \mathrm{kg})$ was given $30 \mathrm{~min}$ before stimulation with compound $48 / 80$ and $2-\mathrm{APB}(60 \mathrm{mg} / \mathrm{kg})$. (d) Gadolinium chloride pre-treatment $(10 \mathrm{mg} / \mathrm{kg}$ ) was given $30 \mathrm{~min}$ before stimulation with compound 48/80 and probenecid (30, 100 , and 300 $\mathrm{mg} / \mathrm{kg}$ ). (a-d lower panel) Histamine in serum was analyzed by the histamine assay. ${ }^{\#} p<0.05$, significantly different from the normal group; ${ }^{*} p<$ 0.05, significantly different from the compound 48/80 group. N, normal mice; Com 48/80, compound 48/80; Moxa, moxibustion; CZP, capsazepine; Solder, soldering instrument; Pro, probenecid; Gd, gadolinium chloride.

transferred into a cell culture flask to seed the fibroblast. The cultures were maintained for $1 \mathrm{~h}$ at $37^{\circ} \mathrm{C}$ in a humidified atmosphere with $5 \% \mathrm{CO} 2$. The supernatant containing the 9 cardiomyocytes was gently removed, counted, and then plated out at $1 \times 10^{6} / \mathrm{ml}$ cardiomyocytes in a 6 -well plate coated with fibronectin.

\section{Western blot analysis}

Heart tissue and cardiomyocyte extracts were prepared using a detergent lysis procedure. Samples were heated at $95^{\circ} \mathrm{C}$ for 5 min, and briefly cooled on ice. Following centrifugation at $15,000 \mathrm{rpm}$ for $5 \mathrm{~min}, 50 \mu \mathrm{g}$ aliquots were resolved by $10 \%$ sodium dodecyl sulfate-polyacrylamide gel electro-phoresis. The resolved proteins were electro-transferred overnight onto

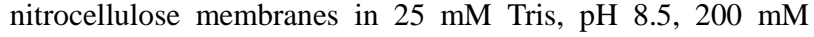
glycerin and $20 \%$ methanol at $25 \mathrm{~V}$. Blots were blocked for at least $2 \mathrm{~h}$ with $1 \times$ PBS containing 5\% non-fat dry milk and then incubated with the TRPV2 antibodies for $1 \mathrm{~h}$ at room temperature. Blots were developed by peroxidase-conjugated secondary antibodies and proteins were visualized by enhanced chemiluminescence procedures (Amersham Biosciences, Piscataway, NJ, USA) according to the manufacturer's instructions.

\section{Confocal laser scanning microscopy}

Heart tissues were immediately fixed with $4 \%$ formaldehyde and embedded in paraffin. After dewaxing and dehydration, sections were blocked with bovine serum albumin followed by a 60 min incubation with anti-rabbit TRPV2 and anti-mouse sarcomeric- $\alpha$ actinin (cardiomyocytes marker) at a concentration of $1 \mu \mathrm{g} / \mathrm{ml}$. The secondary antibodies, FITCconjugated anti-rabbit or TRITC-conjugated anti-mouse IgG (invitrogen), were added to the incubation for $30 \mathrm{~min}$. The mounting medium containing 4', 6-diamidino-2-phenylindole (Vector Laboratories, Burlingame, CA, USA) was used to counterstain DNA. All specimens were examined with a confocal laser-scanning microscope. Sections were coded and randomly analyzed by two blinded observers (Jeong H-J and Nam S-Y).

Fluorescent measurements of the intracellular calcium level To measure the time-dependent levels of intracellular calcium, cardiomyocytes $\left(1 \times 10^{5}\right)$ were pretreated with Fura-2/AM in IMDM containing 10\% FBS for $30 \mathrm{~min}$ and then harvested. After washing twice with calcium free medium (containing 0.5 mM EGTA, an extracellular calcium chelator), approximately $100 \mu \mathrm{l}$ of the cell suspension were placed into a 96-well plate and treated with compound $48 / 80$, histamine $(100 \mu \mathrm{M})$, or probenecid $(100 \mu \mathrm{M})$. The kinetics of the intracellular calcium levels were recorded every $10 \mathrm{~s}$ at $440 \mathrm{~nm}$ (excitation at 360 $\mathrm{nm})$ in a spectrofluorometer.

\section{Statistical analysis}

The experiments shown are a summary of the data from at least three experiments. Statistical analyses were performed using SPSS statistical software (SPSS 11.5, Armonk, NY, USA). Treatment effects were analyzed by an independent t-test and one way ANOVA with Tukey's post hoc test. $p<0.05$ was used to indicate significance.

\section{RESULTS}

\section{Effect of moxibustion on anaphylaxis}

To examine the contribution of moxibustion on anaphylactic reactions, an in vivo model of systemic anaphylactic reaction was applied using compound 48/80 (8 $\mathrm{mg} / \mathrm{kg}$ ) as a systemic fatal anaphylaxis inducer. After the injection of compound $48 / 80$, the mice were monitored for 30 $\mathrm{min}$, and then the mortality rate was determined. Moxibustion was post-stimulated $1(\mathrm{M} \times 1), 2(\mathrm{M} \times 2)$, and $3(\mathrm{M} \times 3)$ times after 0,5 , and $8 \mathrm{~min}$ of compound $48 / 80$ treatment at the Shimen (CV5) acupoint (Fig. 1). As shown in Fig. 1a, an oral administration of saline as a control after compound 48/80 

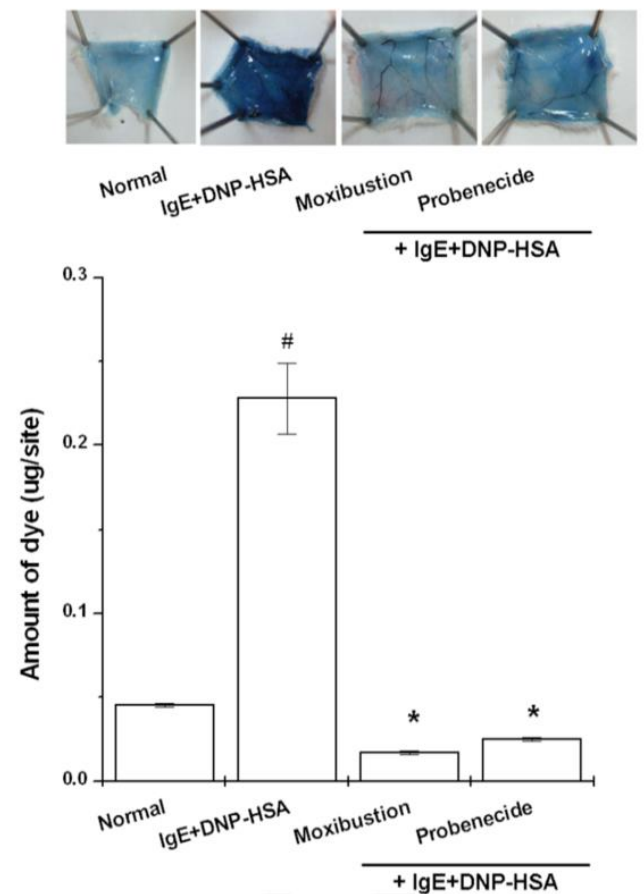

b

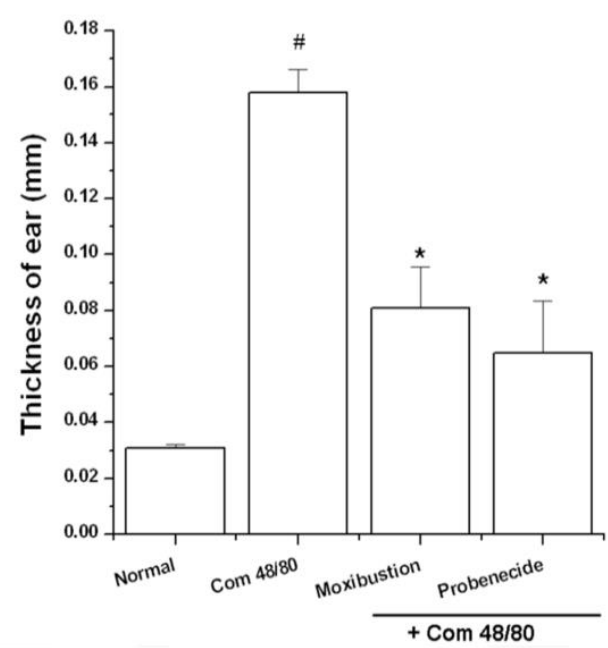

Fig. 5. Effect of moxibustion and probenecid in allergic animal models. (a) Mice were intradermally injected with 100 ng of anti-DNP-IgE. Probenecid $(300 \mathrm{mg} / \mathrm{kg}$ ) was administered intraperitoneally for $1 \mathrm{~h}$ prior to challenge with $1 \mathrm{mg} / \mathrm{ml}$ of antigen (DNP-HSA) containing $4 \%$ Evans blue $(1: 1)$ via the tail vein after $48 \mathrm{~h}$ and then moxibustion applied after $5 \mathrm{~min}$. The amount of effused dye from PCA skin was evaluated. (b) Probenecid $(300 \mathrm{mg} / \mathrm{kg}$ ) was intraperitoneally administered $1 \mathrm{~h}$ prior to compound 48/80 application. $20 \mu \mathrm{l}$ of compound 48/80 was intradermally applied before moxibustion. All data represents the mean \pm S.D. ${ }^{*} p<0.05$, significantly different from the normal group; $* p<0.05$, significantly different from the compound 48/80 group or IgE-DNP-HSA group. $n=6$.

treatment induced a fatal reaction in $100 \%$ of mice in each group. However, moxibustion improved overall survival rates compared with the saline control. The most effective moxibustion treatment was two applications at 5 or 8 min after compound 48/80 treatment (Table 1 and Fig. 2). To specifically assess the thermal effect on anaphylaxis, a soldering instrument $\left(200^{\circ} \mathrm{C}\right.$ indirect, Fig. 3) was applied at the same temperature as moxibustion. The soldering instrument reduced compound 48/80-induced mortality but moxibustion was more effective than the soldering instrument on anaphylaxis (Fig. 2b). Epinephrine (positive control) reduced compound 48/80induced mortality (Fig. 2c).

\section{Moxibustion activates TRPV2 in anaphylaxis}

TRPV1 is well known for its contributions to acute thermal nociception and injury-elicited hyperalgesia (Caterina et al., 2000; Davis et al., 2000). TRPV1 channels are activated by heat, acid, and a large number of chemical stimuli (Hu et al., 2004). To investigate the role of TRPV1 on the inhibitory effects of moxibustion, the effect of capsazepine (a TRPV1 antagonist) on anaphylaxis was examined. Interestingly, capsazepine significantly improved overall survival rates compared with the moxibustion or soldering instrument stimulation groups (Fig. 4a and b, upper). Histamine release was significantly reduced in moxibustion and moxibustion plus capsazepine groups compared with the compound 48/80 group (Fig. 4a, lower panel, $p<0.05$ ). In mice treated with a soldering instrument, however, capsazepine did not affect histamine release (Fig. 4b, lower). The effect of 2-APB (an activator of TRPV1, TRPV2, and TRPV3) was applied to confirm the relationship between TRPVs and moxibustion on anaphylaxis. 2-APB alone did not affect mortality. However, when capsazepine and 2-APB were administered for $30 \mathrm{~min}$, the mortality rate and histamine release induced by compound $48 / 80$ were significantly reduced (Fig. $4 c, p<0.05$ ). Thus, we studied the role of TRPV2 (a molecule sensitive to temperatures above $52^{\circ} \mathrm{C}$ ) on compound 48/80-induced anaphylaxis. Probenecid (a TRPV2 agonist) increased the survival rate and significantly reduced histamine release in a dose-dependent manner (Fig. 4d, $p<0.05$ ). However, the increased survival rate increased due to probenecid was completely inhibited by treatment with gadolinium chloride (a TRPV blocker) (Fig. 4d).

\section{Effect of moxibustion and probenecid on allergic animal models}

The effects of moxibustion and probenecid were examined in various allergic animal models. Moxibustion and probenecid significantly reduced the PCA reaction, a common murine anaphylaxis model (Fig. 5a, $p<0.05$ ). In addition, the effect of moxibustion and probenecid were tested on the compound 48/80-induced ear swelling response. Compound 48/80 significantly induced an ear swelling response, but the ear swelling response was significantly reduced by moxibustion and probenecid (Fig. 5b, $p<0.05$ ).

\section{Effect of moxibustion and probenecid on epinephrine secretion}

Epinephrine typically used in the treatment for anaphylaxis. Thus, the effect of moxibustion and probenecid were investigated to determine their ability to increase epinephrine secretion in anaphylaxis. As shown in Fig. 6a, epinephrine levels were significantly increased by moxibustion or probenecid $(p<0.05)$. The role of the epinephrine signaling pathway on the regulatory effect of moxibustion and probenecid in anaphylaxis was investigated. The mice were 
a

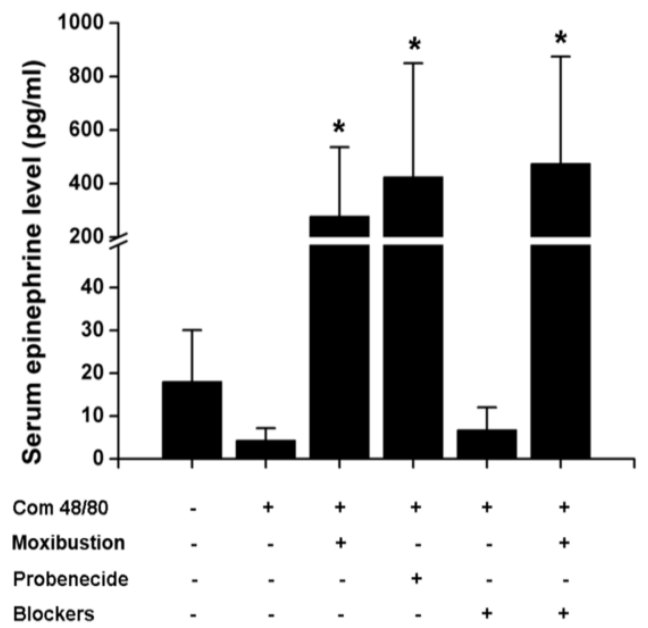

b

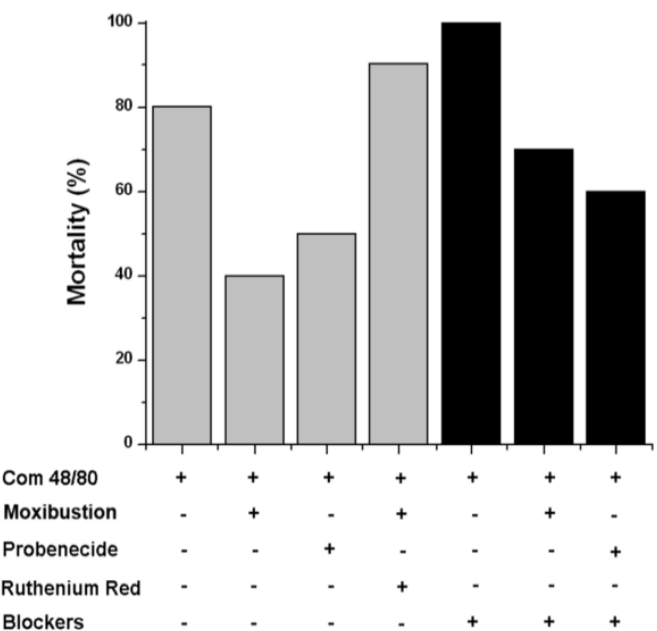

Fig. 6. Effect of moxibustion and probenecid on epinephrine secretion. A drenergic receptor blockers (mixture of phentolamine $10 \mathrm{mg} / \mathrm{kg}$ and metoprolol $20 \mathrm{mg} / \mathrm{kg}$ ) and ruthenium red $(50 \mathrm{mg} / \mathrm{kg}$ ) were given $30 \mathrm{~min}$ before compound 48/80, moxibustion, or probenecid treatment. (a) Epinephrine in serum was analyzed using an Epinephrine Assay Kit. (b) Mortality (\%) was monitored for 20 min. * $p<0.05$, significantly different from the compound $48 / 80$ group. $n=10$. Com 48/80, compound 48/80; Blockers, adrenergic receptor blockers.

a

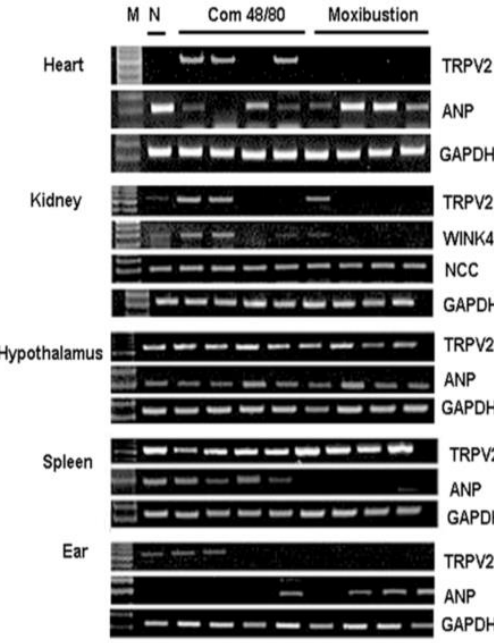

b

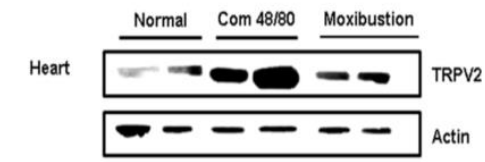

c
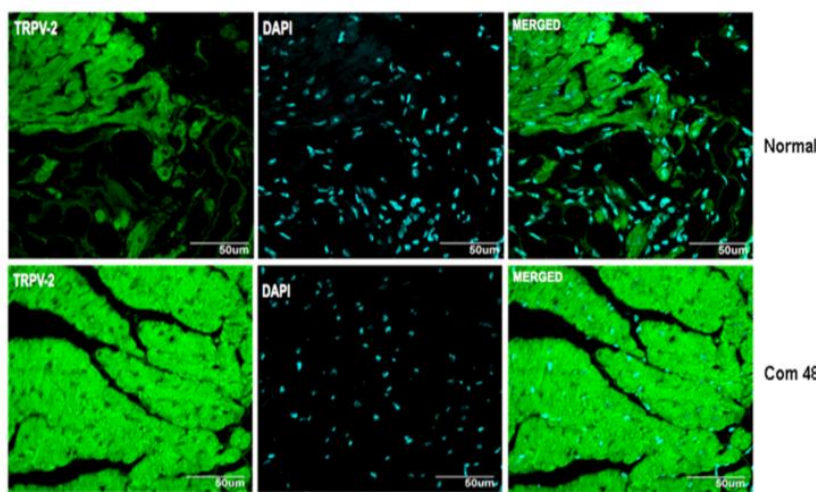

TRPV 2
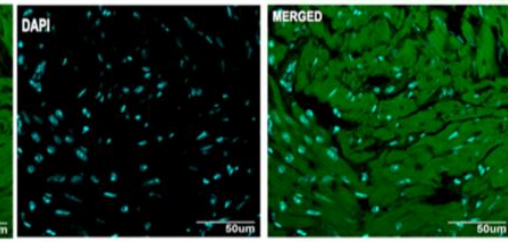

Fig. 7. Moxibustion suppresses heart TRPV2 levels in a compound 48/80-induced anaphylaxis model. (a) The mRNA expressions of TRPV2, ANP, WINK4, and NCC in various organ tissues from both compound 48/80 and compound 48/80 + moxibustion groups were analyzed using reverse transcription-PCR. The expression was normalized to GAPDH mRNA expression. (b) The expression of TRPV2 protein was analyzed by Western blot analysis in heart tissue from mice under anaphylaxis. (c) The TRPV $2^{+}$(green) cells from heart tissues were examined with a confocal laserscanning microscope (scale bar $=50 \mu \mathrm{m}$ ). Results are representative of three independent experiments. $\mathrm{M}$, marker; $\mathrm{N}$, normal mice; compound 48/80; Moxibustion, compound 48/80 + moxibustion.

monitored for $20 \mathrm{~min}$, and then the mortality rate was determined. As shown in Fig. 6b, mice administered the adrenergic receptor blockers died more quickly than compound48/80-treated mice. In addition, increased survival rates from moxibustion and probenecid were partially decreased by application of the adrenergic receptor blockers (Fig. 6b). Ruthenium red completely abolished moxibustioninduced survival (Fig. 6b). Anaphylaxis drastically decreases blood pressure, resulting in hypotension. Okazaki et al. reported that moxibustion increases blood pressure (Okazaki et al., 1990). To investigate the role of TRPV 2 on blood pressure, blood pressure was measured in probenecid-administered mice. The decreased blood pressure from treatment with compound $48 / 80$ was increased by probenecid administration (data not shown).

Effect of moxibustion and probenecid on epinephrine secretion 
a

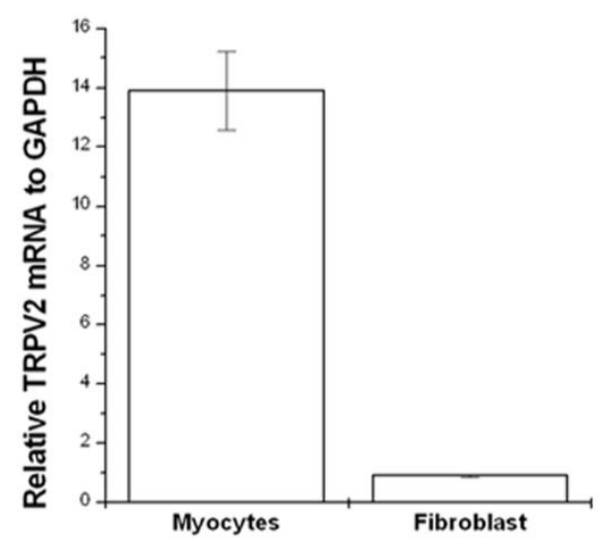

b

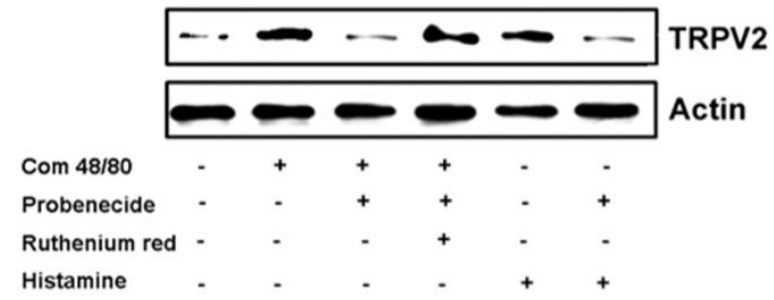

C

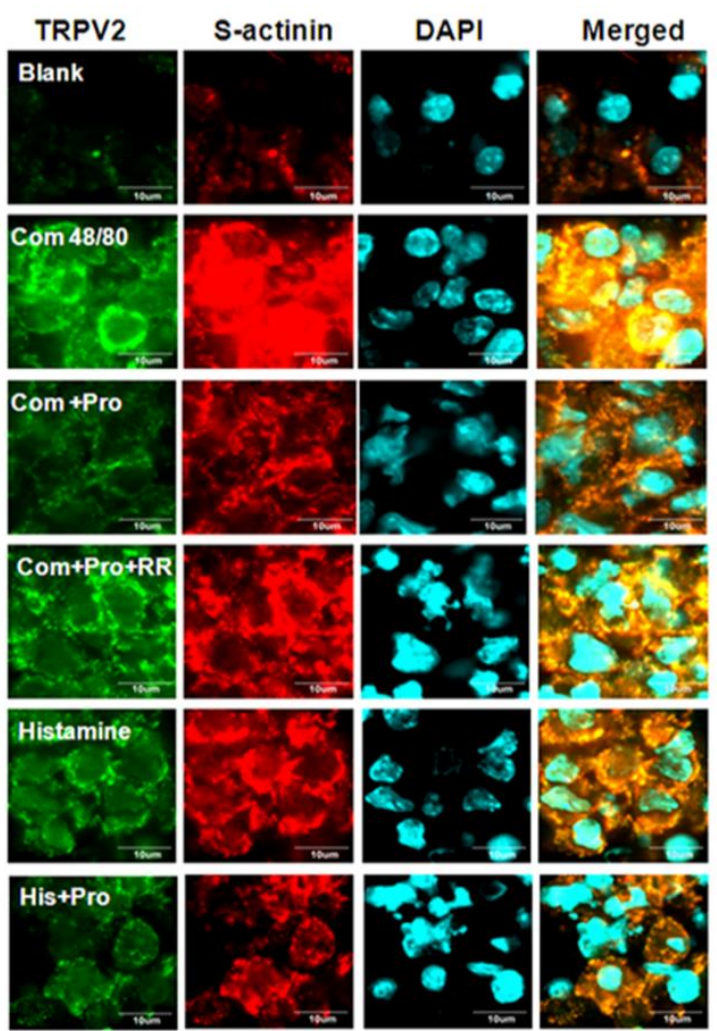

Fig. 8. Probenecid suppresses compound 48/80-induced TRPV2 expression in cardiomyocytes. Embryonic cardiomyocytes and fibroblasts from the heart were analyzed using quantitative real-time PCR analysis for TRPV2. (a) The mRNA expression of TRPV2 in fibroblast and cardiomyocytes. The cells were pretreated with ruthenium red $(2 \mu \mathrm{M})$ for 20 min before compound 48/80, histamine $(100 \mu \mathrm{M})$, or probenecid $(100 \mu \mathrm{M})$ stimulation. The expression of TRPV2 protein was analyzed using Western blot analysis (b) and immunocytochemistry analysis (c). The TRPV2 ${ }^{+}$(FITC) and sarcomeric- $\alpha$ actinin $^{+}$(TRITC) cells were examined with a confocal laser-scanning microscope. Representative photomicrographs were examined at $60 \times$ magnification. $($ Scale bar $=10 \mu \mathrm{m}$ ). Com 48/80, compound 48/80, Com + Pro, compound 48/80 + probenecid; Com + Pro + RR, compound $48 / 80$ + probenecid + ruthenium red; His + Pro, histamine + probenecid.

Epinephrine typically used in the treatment for anaphylaxis. Thus, the effect of moxibustion and probenecid were investigated to determine their ability to increase epinephrine secretion in anaphylaxis. As shown in Fig. 6a, epinephrine levels were significantly increased by moxibustion or probenecid $(p<0.05)$. The role of the epinephrine signaling pathway on the regulatory effect of moxibustion and probenecid in anaphylaxis was investigated. The mice were monitored for $20 \mathrm{~min}$, and then the mortality rate was determined. As shown in Fig. 6b, mice administered the adrenergic receptor blockers died more quickly than compound48/80-treated mice. In addition, increased survival rates from moxibustion and probenecid were partially decreased by application of the adrenergic receptor blockers (Fig. 6b). Ruthenium red completely abolished moxibustioninduced survival (Fig. 6b). Anaphylaxis drastically decreases blood pressure, resulting in hypotension. Okazaki et al. reported that moxibustion increases blood pressure (Okazaki et al., 1990). To investigate the role of TRPV2 on blood pressure, blood pressure was measured in probenecid-administered mice. The decreased blood pressure from treatment with compound 48/80 was increased by probenecid administration (data not shown).

Probenecid suppresses compound 48/80-induced TRPV2 over-expression in cardiomyocytes

To determine the TRPV2-expressing cells in heart tissue, fibroblast and cardiomyocytes were isolated from heart tissue.
TRPV2 mRNA was constitutively expressed in cardiomyocytes but not fibroblasts (Fig. 8a). Compound 48/80 markedly increased TRPV2 protein expression (Fig. 8b). The role of histamine released by compound 48/80 was assessed as well. Histamine also increased TRPV2 expression. However, probenecid decreased compound $48 / 80$ or histamine-induced TRPV2 expression in cardiomyocytes (Fig. 8b). The immunocytochemical analysis of the cardiomyocytes also revealed that TRPV2 was highly expressed in the compound 48/80 group but decreased in probenecid treated group (Fig. 8c). Moxibustion also decreased TRPV2 protein expression in cardiomyocytes of heart tissue (Fig. 9). Epinephrine increases blood pressure (Weissgerber, 2008). Therefore, the effect of epinephrine on compound 48/80-indued TRPV2 overexpression was investigated. Epinephrine significantly decreased compound 48/80- or histamine-induced TRPV2 expression through the modulation of adrenergic receptors (ADR $\alpha 2 \mathrm{~A}$ and ADR $\beta 1$ ) in cardiomyocytes (Fig. 10a-c, $p<$ $0.05)$. Epinephrine also significantly decreased ANP expression (Fig. 10b, $p<0.05$ ). Ruthenium red did not affect the TRPV2 expression (Fig. 10a).

Probenecid decreases intracellular $\mathrm{Ca}^{2+}$ levels induced by compound 48/80 in cardiomyocytes

TRPV2 is a moderately calcium-selective cationic channel and increases in intracellular $\mathrm{Ca}^{2+}$ are sufficient for lowering blood pressure (Murata et al., 2004). Thus, the regulatory effect of probenecid on $\mathrm{Ca}^{2+}$ influx in compound 48/80-stimulated 

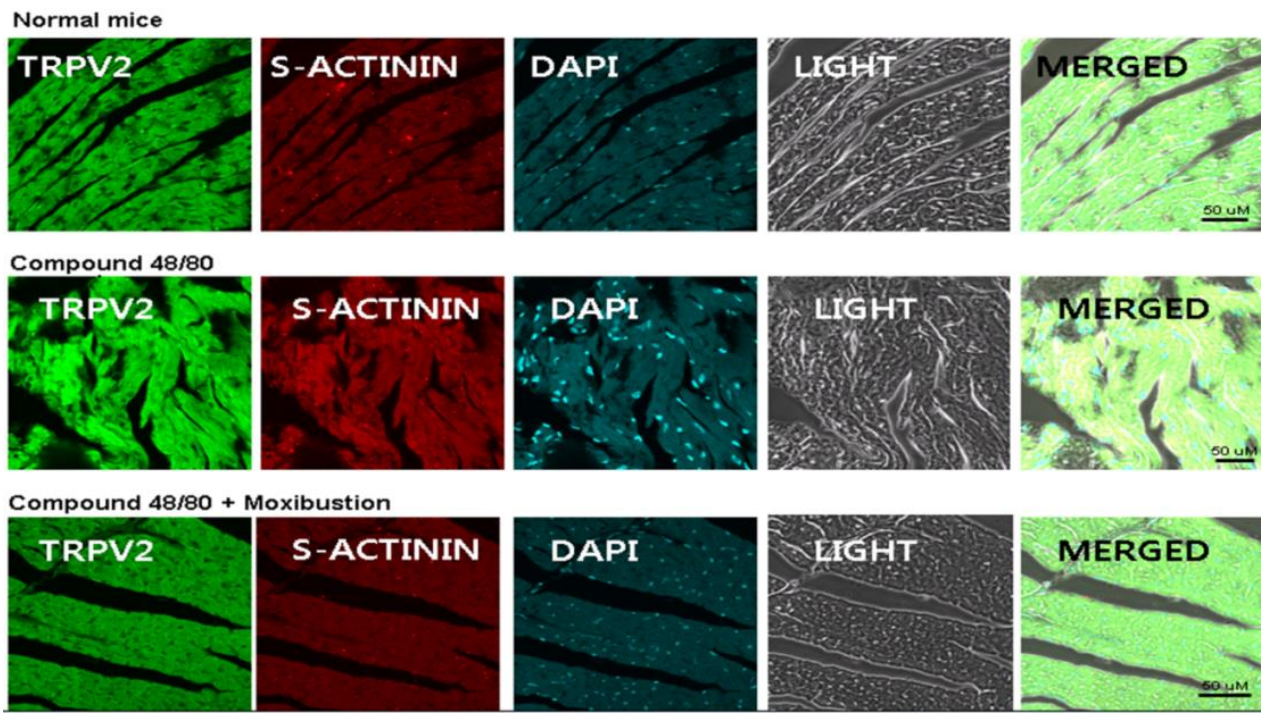

Fig. 9. Moxibustion suppresses compound 48/80-induced TRPV2 expression in cardiomyocytes of heart tissue. The expression of TRPV2 protein was analyzed using immunohistochemistry analysis. The TRPV2+ (FITC) and sarcomeric- $\alpha$ actinin + (TRITC) cells were examined with a confocal laserscanning microscope. The merged image indicates the colocalization of cardiomyocytes and TRPV2. Representative photomicrographs were examined at $60 \times$ magnification. S-ACTININ, sarcomeric- $\alpha$ actinin. (scale bar $=50 \mu \mathrm{m}$ ).

cardiomyocytes was examined. Stimulation with compound $48 / 80$ increased $\mathrm{Ca}^{2+}$ release from intracellular stores (in 0.5 mM EGTA containing media), whereas probenecid decreased the level of intracellular $\mathrm{Ca}^{2+}$ increased by compound $48 / 80$ (Fig. 11). Probenecid alone increased the level of intracellular $\mathrm{Ca}^{2+}$.

\section{DISCUSSION}

Anaphylaxis is a severe and potentially life-threatening systemic allergic reaction mostly encountered and managed at emergency departments (Calderón et al., 2013). The most important requirements in the treatment of anaphylaxis are prompt diagnosis and the maintenance of coronary and cerebral perfusion, but these can be difficult or even impossible to accomplish (Schummer et al., 2004). In this study, moxibustion known for its thermal effect attenuated the anaphylactic reaction. Physical stresses, such as heat, can increase sympathetic nerve stimulation and epinephrine release, in turn increasing blood pressure, heart rate, and respiratory rate (Vandana et al., 2013). TRPVs induce vasoconstriction and vasodilatation (Inoue et al., 2008). TRPV1 $\left(>43^{\circ} \mathrm{C}\right)$, TRPV2 (> $\left.52^{\circ} \mathrm{C}\right)$, and TRPV3 $\left(<39^{\circ} \mathrm{C}\right)$ are especially activated by thermal stimulation. A previous study indicated that a TRPV1 agonist, capsaicin increases calcium uptake and induces vasoconstriction (Cavanaugh et al., 2011). Capsazepine was therefore used in this study to investigate the role of TRPV1 in moxibustion. However, when capsazepine was treated with moxibustion, the survival rate was higher compared to moxibustion alone. 2-APB can activate TRPV1, TRPV2, and TRPV3 (Hu et al., 2004). When TRPV1-3 are activated by 2 $\mathrm{APB}$, the survival rate was unchanged compared to the compound $48 / 80$ group. In contrast to, the co-treatment of 2APB and capsazepine reduced compound 48/80-induced mortality. Ruthenium red completely inhibited anti-ear swelling response was significantly reduced by moxibustion and probenecid anaphylactic reaction compared with the moxibustion group (Fig. 5b, $p<0.05$ ). This suggests TRPV2 is an important factor in the anti-anaphylactic effect of moxibustion because TRPV3 contributes to the normal heat response.

Couto et al. (2013) recently reported that the inhalation of capsaicin is associated with parasympathetic broncho constriction, mucus hypersecretion, vasodilatation, and the sensation of dyspnea. Activated TRPV1 induces mast cell degranulation and releases proinflammatory mediators including histamine (Andrade et al., 2008; Tóth et al., 2009). In this study, capsazepine did not affect compound 48/80-induced mortality by itself. Based upon these results, we hypothesized that TRPV1 and TRPV2 were activated by moxibustion and that the TRPV1 blockade by capsazephine increased survival rate through the modulation of TRPV2 activity. This hypothesis was supported by the ability of probenecid (a TRPV2 agonist) to inhibit the effect of compound $48 / 80$ on anaphylaxis. Therefore, TRPV1 exerted a negative effect and TRPV2 exerted a positive effect on anaphylaxis. This is the first study to show that the anti-anaphylactic effect of moxibustion is potentially associated with the activity of TRPV2.

In this study, the anti-anaphylactic effect of moxibustion was higher than that from the soldering instrument, which did not inhibit histamine release. Therefore, in addition to its thermal effects, moxibustion has various regulatory mechanisms on anaphylactic reaction. Anaphylactic shock decreases blood flow and induces severe arterial hypotension (Johansson et al., 2001). The amount of histamine released from mast cells upon anaphylactic challenge is associated with the reduction of blood pressure and body temperature within the first $10 \mathrm{~min}$ of anaphylaxis (Olivera et al., 2010). Epinephrine and vasopressin are drugs that increase blood pressure and are used for the treatment of anaphylactic shock (Kim et al., 2013; Schummer et al., 2004). In this study, moxibustion and probenecid significantly increased the levels of epinephrine. Survival rates increased by moxibustion and probenecid were partially abolished by adrenergic receptor blockers. However, ruthenium red and gadolinium chloride fully inhibited moxibustion and probenecid-induced antianaphylactic effects. The blood pressure in probenecid treated mice was significantly increased compared to mice treated with compound 48/80. Thus, the beneficial effects of moxibustion on anaphylaxis might be derived from the secretion of epinephrine via activation of TRPV2. 
a

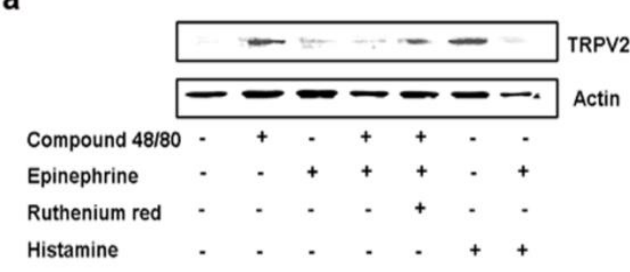

b

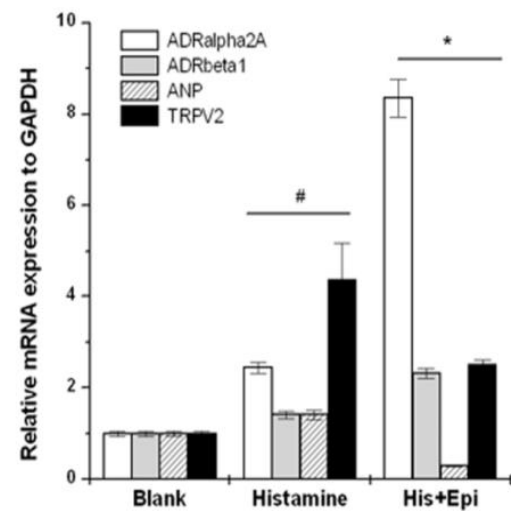

C

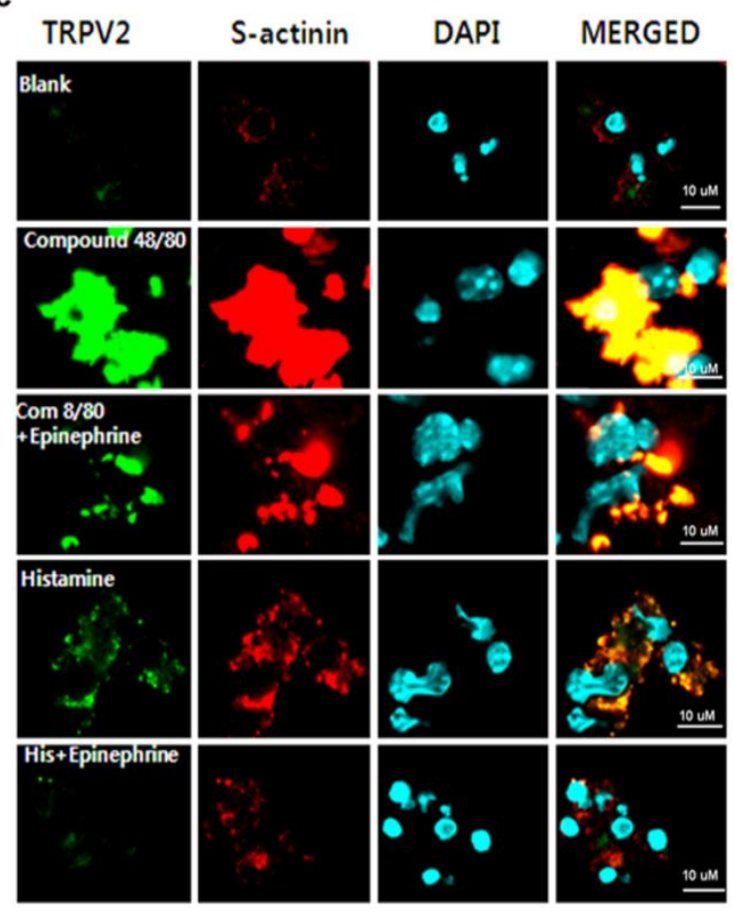

Fig. 10. Epinephrine suppresses compound 48/80-induced TRPV2 expression in cardiomyocytes. Embryonic cardiomyocytes from the heart were isolated and the cells pretreated with ruthenium red $(2 \mu \mathrm{M})$ for 20 min before compound $48 / 80$, histamine $(100 \mu \mathrm{M})$, or epinephrine $(5 \mathrm{nM})$ treatment. (a) The expression of TRPV2 protein was analyzed using Western blot analysis. (b) Quantitative real-time PCR analysis for TRPV2, ANP, ADR 2 A, and ADR $\beta 1$. Data represents the mean \pm S.D. (c) Immunocytochemistry analysis. The TRPV2 ${ }^{+}\left(\right.$FITC) and sarcomeric- $\alpha$ actinin ${ }^{+}$(TRITC) cells were examined with a confocal laser-scanning microscope. The merged image indicated the colocalization of cardiomyocytes and TRPV2. Representative photomicrographs were examined at $60 \times$ magnification. (scale bar $=10 \mu \mathrm{m}$ ). His + Epi, histamine + epinephrine. ${ }^{\#} p<0.05$, significantly different from the blank group; ${ }^{*} p<0.05$, significantly different from the histamine group.

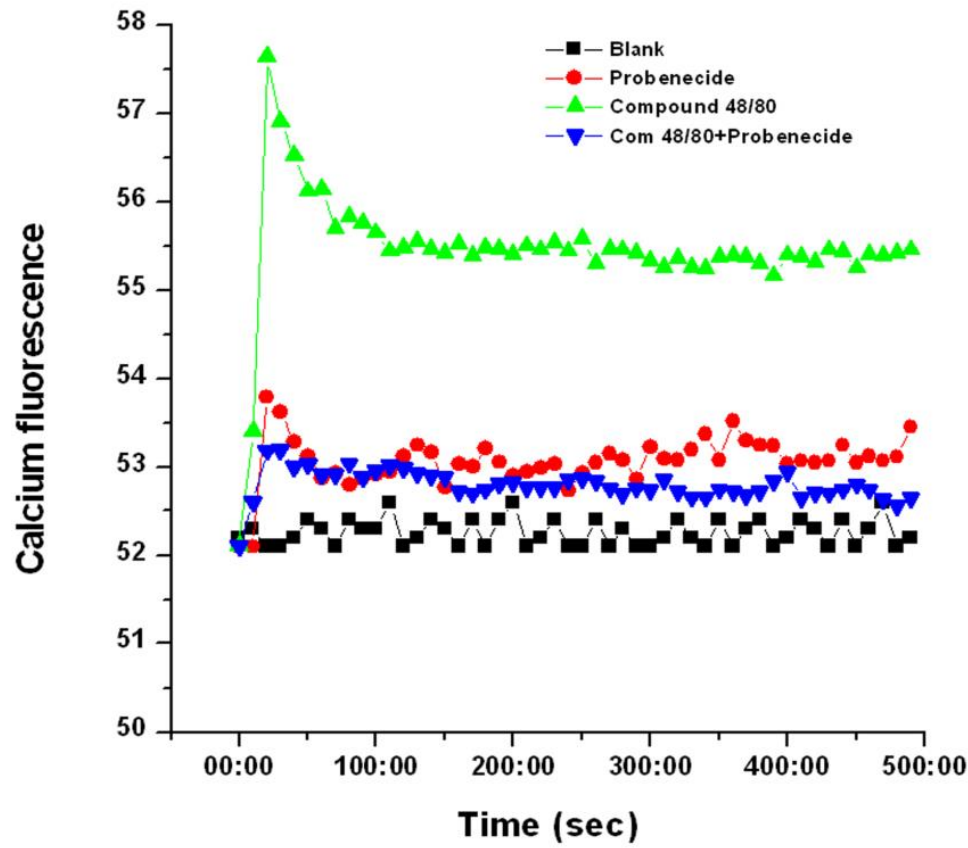

Fig. 11. Probenecid decreases intracellular calcium levels induced by compound 48/80 in cardiomyocytes. Cardiomyocytes were treated with compound 48/80, histamine $(100 \mu \mathrm{M})$, or probenecid $(100 \mu \mathrm{M})$. The kinetics of intracellular calcium was measured every $10 \mathrm{~s}$ for $500 \mathrm{~s}$. Each datum represents the mean \pm S.D. of three independent experiments. Blank, unstimulated cells.

TRPV2 is expressed in various organs including the heart, brain, vascular myocytes, and visceral organ. The heart is an important target organ in anaphylaxis and TRPV2 is present and active in cardiomyocytes (Koch et al., 2012). Activation of TRPV2 located within and around the cardiovascular system leads to vasodilatation or vasoconstriction through different pathways (Robbins et al., 2013). In addition, TRPV2-/- mice have depressed myocardial performance (Rubinstein et al., 2014). In the heart, TRPV2 over-expression induces dystrophic cardiomyopathy; however, stimulation under physiologic 
conditions improves cardiac function (Robbins et al., 2013). Baylie and Brayden reported that TRPV2 contributes to vasoconstriction in vascular smooth muscle. Probenecid has been used to treat for cardiomyopathy (Baylie and Brayden, 2001; Robbins et al., 2013). The cardiac effects by anaphylaxis are also related to the histamine released by mast cell degranulation (Felix et al., 1991). In this study, TRPV2 was over-expressed by compound $48 / 80$ and histamine but this increased TRPV2 expression was decreased by moxibustion and probenecid to a steady-state in cardiomyocytes. Therefore, the regulation of TRPV2 expression could be useful for treating anaphylaxis. Moxibustion may mediate its anti-anaphylactic effects through reduction in TRPV2 over-expression induced by compound $48 / 80$.

Intracellular $\mathrm{Ca}^{2+}$ plays a central role in various biological processes. In the heart, $\mathrm{Ca}^{2+}$ is an important activator of normal muscle contraction. Excessive increases in intracellular $\mathrm{Ca}^{2+}$ induces hypotension, arrhythmias, hypertrophy, apoptosis, and cardiac remodeling (Murata et al., 2004). Therefore, the modulation of $\mathrm{Ca}^{2+}$ homeostasis could be useful for the therapeutic manipulation of these pathophysiological processes. TRPV2 is a $\mathrm{Ca}^{2+}$ selective channel activated by noxious heat $\left(>52{ }^{\circ} \mathrm{C}\right)$ and the activation of TRPV2 increases $\mathrm{Ca}^{2+}$ influx in neuronal cells localized to the dorsal root ganglia (Shibasaki et al., 2010). In cardiomyocytes, the stimulatory effects of probenecid on cytosolic $\mathrm{Ca}^{2+}$ and myocyte contractility involve activation of the TRPV2 channel (Koch et al., 2012). Furthermore, the over-expression of TRPV2 in the heart caused cardiac contractile dysfunction due to $\mathrm{Ca}^{2+}$ overloading (Iwata et al., 2003). In this study, compound $48 / 80$ induced TRPV2 over-expression and excessively increased intracellular $\mathrm{Ca}^{2+}$. These increases were reduced by probenecid. Thus, TRPV2 over-expression by compound 48/80 induces anaphylaxis through increasing intracellular $\mathrm{Ca}^{2+}$ levels in cardiomyocytes.

Traditional Oriental medicine believes that a person is as a whole. The organs and limbs communicate and interact through the meridian system. The meridian system consists of channels and collaterals - pathways for communications between internal and external parts of the body, the flow of qi through blood, and general regulation of the whole body. Moxibustion is related to physiological meridians, cutaneous regions, and acupoints. In this study, moxibustion had an anti-anaphylactic effect through the promotion of epinephrine secretion and the regulation of intracellular $\mathrm{Ca}^{2+}$ by modulating the expression and activation of TRPV2. Therefore, these results provide additional evidence that moxibustion may be an effective new

approach for the treatment of anaphylaxis. However, further studies are needed to assess the distinct mechanisms and effects of moxibustion prior to its clinical use in humans.

\section{ACKNOWLEDGEMENTS}

This research was supported by Basic Science Research Program through the National Research Foundation of Korea (NRF) funded by the Ministry of Education, Science and Technology (2012R1A1A2A10044645) and the National Research Foundation of Korea (NRF) grant funded by the Korea government (MSIP) (No. 2005-0049404).

\section{CONFLICT OF INTEREST}

The authors do not have any conflict of interest in the present study.

\section{REFERENCES}

Andrade EL, Luiz AP, Ferreira J, Calixto JB. Pronociceptive response elicited by TRPA1 receptor activation in mice. Neuroscience. 2008;152:511-520.

Baylie RL, Brayden JE. TRPV channels and vascular function. Acta Physiol (Oxf). 2001;203:99-116.

Calderón E, Méndez J, Nazario S. Anaphylaxis diagnosis and treatment at an emergency department in Puerto Rico. P R Health Sci J. 2013;32:170-174.

Caterina MJ, Rosen TA, Tominaga M, Brake AJ, Julius D. A capsaicin-receptor homologue with a high threshold for noxious heat. Nature. 1999;398:436-441.

Caterina MJ, Leffler A, Malmberg AB, Martin WJ, Trafton J, Petersen-Zeitz KR, Koltzenburg M, Basbaum AI, Julius D. Impaired nociception and pain sensation in mice lacking the capsaicin receptor. Science. 2000;288:306-313.

Cavanaugh DJ, Chesler AT, Jackson AC, Sigal YM, Yamanaka H, Grant R, O'Donnell D, Nicoll RA, Shan NM, Julius D, Basbaum AI. Trpv1 reporter mice reveal highly restricted brain distribution and functional expression in arteriolar smooth muscle cells. J Neurosci. 2011;31:5067-5077.

Choi GS, Han JB, Park JH, Oh SD, Lee GS, Bae HS, Jung SK, Cho YW, Ahn HJ, Min BI. Effects of moxibustion to zusanli (ST36) on alteration of natural killer cell activity in rats. Am J Chin Med. 2004;32:303-312.

Couto M, de Diego A, Perpiñi M, Delgado L, Moreira A. Cough reflex testing with inhaled capsaicin and TRPV1 activation in asthma and comorbid conditions. J Investig Allergol Clin Immunol. 2013;23:289-301.

Davis JB, Gray J, Gunthorpe MJ, Hatcher JP, Davey PT, Overend P, Harries MH, Latcham J, Clapham C, Atkinson K, Hughes SA, Rance K, Grau E, Harper AJ, Pugh PL, Rogers DC Bingham S, Randall A, Sheardown SA. Vanilloid receptor-1 is essential for inflammatory thermal hyperalgesia. Nature. 2000;405:183-187.

Deng H, Shen X. The Mechanism of Moxibustion: Ancient Theory and Modern Research. Evid Based Complement Alternat Med. 2013;2013:379291.

Felix SB, Baumann G, Niemczyk M, Hashemi T, Ochsenfeld G, Ahmad Z, Shirani S, Blömer H. Effects of histamine H1- and H2-receptor antagonists on cardiovascular function during systemic anaphylaxis in guinea pigs. Agents Actions. 1991;32:245-252.

Hu HZ, Gu Q, Wang C, Colton CK, Tang J, Kinoshita-Kawada M, Lee LY, Wood JD, Zhu MX. 2-aminoethoxydiphenyl borate is a common activator of TRPV1, TRPV2, and TRPV3. J Biol Chem. 2004;279:35741-35748.

Inoue R, Hai L, Honda A. Pathophysiological implications of transient receptor potential channels in vascular function. Curr 
Opin Nephrol Hypertens. 2008;17:193-198.

Iwata Y, Katanosaka Y, Arai Y, Komamura K, Miyatake K, Shigekawa M. A novel mechanism of myocyte degeneration involving the $\mathrm{Ca} 2+-$ permeable growth factor-regulated channel. J Cell Biol. 2003;161:957-967.

Johansson SG, Hourihane JO, Bousquet J, Bruijinzeel-Koomen C, Dreborg S, Haahtela T, Kowalski ML, Mygind N, Ring J, van Cauwenberge $\mathrm{P}$, van Hage-Hamsten $M$, Wüthrich $B$, EAACI (the European Academy of Allergology and Cinical Immunology) nomenclature task force. A revised nomenclature for allergy. An EAACI position statement from the EAACI nomenclature task force. Allergy. 2001;56:813-824.

Kim CW, Figueroa A, Park CH, Kwak YS, Kim KB, Seo DY, Lee HR. Combined effects of food and exercise on anaphylaxis. Nutr Res Pract. 2013;7:347-351.

Kim J, Kang D, Kang M, Kang B, Kang EB, Kang J, Go Y, Ko W, Kwak J, Ku H, Gwon SY, Gi Y, Kim G, Kim G, Kim K, Kim K, Kim DH, Kim M, Kim MC, Kim S, Kim S, Kim S, Kim S, Kim Y, Kim J, Kim J, Nam S, Doh T, Do H, Moon GY, Min G, Park KK, Park M, Park S, Park I, Park JG, Park J, Park JG, Park J, Park T, Bae J, Byun J, Seo SW, Seo H, Son K, Song CG, Shin HY, Sim EK, An S, Ahn J, Yang JY, Ok D, Yoon G, Yoon SS, Yoon Y, Yoon J, Lee KE, Lee K, Lee $\mathrm{D}$, Lee MH, Lee S, Lee S, Lee SH, Lee SY, Lee S, Lee Y, Lee J, Lee JS, Lee J, Lee J, Lee J, Lee CH, Lee CH, Lim S, Lim S, Rheem HG, Jun H, Jeong B, Chung I, Jung J, Cho S, Cho W, Cho E, Joo S, Ji H, Cheon S, Choi I, Choi J, Choi JH, Han N, Han S, Huh E, Hong YJ, Hong J, Hwang M, Moon PD. A comparison of the effects of dexamethasone-pharmacopuncture and dexamethasone-oral administration based on traditional Korean medicine theory on anaphylactic reaction in mice. TANG. 2013;3:e24.

Koch SE, Gao X, Haar L, Jiang M, Lasko VM, Robbins N, Cai W, Brokamp C, Varma P, Tranter M, Liu Y, Ren X, Lorenz JN, Wang HS, Jones WK, Rubinstein J. Probenecid: novel use as a non-injurious positive inotrope acting via cardiac TRPV2 stimulation. J Mol Cell Cardiol. 2012;53:134-144.

Lee SG, Lee H, Nam TG, Eom SH, Heo HJ, Lee CY, Kim DO. Neuroprotective effect of caffeoylquinic acids from Artemisia princeps Pampanini against oxidative stress-induced toxicity in PC-12 cells. J Food Sci. 2011;76:C250-256.

Lewinter RD, Scherrer G, Basbaum AI. Dense transient receptor potential cation channel, vanilloid family, type 2 (TRPV2) immunoreactivity defines a subset of motoneurons in the dorsal lateral nucleus of the spinal cord, the nucleus ambiguus and the trigeminal motor nucleus in rat. Neuroscience. 2008;151:164-173.

Murata M, Cingolani E, McDonald AD, Donahue JK, Marbán E. Creation of a genetic calcium channel blocker by targeted gem gene transfer in the heart. Circ Res. 2004;95:398-405.
Muraki K, Iwata Y, Katanosaka Y, Ito T, Ohya S, Shigekawa M, Imaizumi Y. TRPV2 is a component of osmotically sensitive cation channels in murine aortic myocytes. Circ Res. 2003;93:829-838.

Okazaki M, Aizawa S, Yamauchi M, Oguchi K. Effects of single moxibustion on cutaneous blood vessel and microvascular permeability in mice. Am $J$ Chin Med. 1990;18:121-130.

Olivera A, Eisner C, Kitamura Y, Dillahunt S, Allende L, Tuymetova G, Walford W, Meylan F, Diesner SC, Li L, Schnermann J, Proia RL, Rivera J. Sphingosine kinase 1 and sphingosine-1-phosphate receptor 2 are vital to recovery from anaphylactic shock in mice. J Clin Invest. 2010;120:1429-1440.

Robbins N, Koch SE, Rubinstein J. Targeting TRPV1 and TRPV2 for potential therapeutic interventions in cardiovascular disease. Transl Res. 2013;161:469-476.

Rubinstein J, Lasko VM, Koch SE, Singh VP, Carreira V, Robbins N, Patel AR, Jiang M, Bidwell P, Kranias EG, Jones WK, Lorenz JN. Novel Role of Transient Receptor Potential Vanilloid 2 in the Regulation of Cardiac Performance. Am J Physiol Heart Circ Physiol. 2014;306:H574-H584.

Schummer W, Schummer C, Wippermann J, Fuchs J. Anaphylactic shock: is vasopressin the drug of choice? Anesthesiology. 2004;101:1025-1027.

Shibasaki K, Murayama N, Ono K, Ishizaki Y, Tominaga M. TRPV2 enhances axon outgrowth through its activation by membrane stretch in developing sensory and motor neurons. J Neurosci. 2010;30:4601-4612.

Takayama S, Seki T, Watanabe M, Takashima S, Sugita N, Konno S, Takeda T, Arai H, Yambe T, Yaegashi N, Yoshizawa M, Maruyama S, Nitta S. Changes of blood flow volume in the superior mesenteric artery and brachial artery with abdominal thermal stimulation. Evid Based Complement Alternat Med. 2011;2011:214089.

Tóth BI, Géczy T, Griger Z, Dózsa A, Seltmann H, Kovács L, Nagy L, Zouboulis CC, Paus R, Bíró T. Transient receptor potential vanilloid-1 signaling as a regulator of human sebocyte biology. J Invest Dermatol. 2009;129:329-339.

Vandana B, Saraswathy L, Suseeladevi GK, Sundaram KR, Kumar H. Positive impact of integrated amrita meditation technique on heart rate, respiratory rate and $\operatorname{IgA}$ on young healthy adults.TANG. 2013;3:e13.

Weissgerber AJ. Methylene blue for refractory hypotension: a case report. AANA J. 2008;76:271-274. 